\title{
Elementos humboldtianos en las teorías de la religión y de la magia de Konrad Th. Preuss
}

Paulina Alcocer

\section{(2) OpenEdition \\ 1 Journals}

Edición electrónica

URL: http://journals.openedition.org/jsa/2746

DOI: 10.4000/jsa.2746

ISSN: 1957-7842

Editor

Société des américanistes

\section{Edición impresa}

Fecha de publicación: 1 enero 2002

Paginación: 47-68

ISSN: 0037-9174

\section{Referencia electrónica}

Paulina Alcocer, «Elementos humboldtianos en las teorías de la religión y de la magia de Konrad Th. Preuss », Journal de la société des américanistes [En línea], 88 | 2002, Publicado el 05 enero 2007, consultado el 20 abril 2019. URL : http://journals.openedition.org/jsa/2746 ; DOI : 10.4000/jsa.2746 


\title{
ELEMENTOS HUMBOLDTIANOS EN LAS TEORÍAS DE LA RELIGIÓN Y DE LA MAGIA DE KONRAD TH. PREUSS
}

\author{
Paulina ALCOCER *
}

Este artículo propone la filosofía del lenguaje de Wilhelm von Humboldt como fundamentación de las teorías de la religión y de la magia del etnólogo alemán Konrad Th. Preuss. Con el fin de mostrar la afinidad de sus pensamientos, se ofrece una exposición comparativa de sus respectivos métodos para el estudio de la actividad del « Geist » y la " cultura intelectual ». A partir del análisis de los conceptos "modo de pensar mágico-religioso » y " concepciones complejas ", propuestos por Preuss, se establece su relación con las nociones humboldtianas sobre el proceso de formación de la palabra y sobre el papel de la lengua y del discurso en la constitución de la cosmovisión.

Palabras Claves : historia de la antropología, Konrad Th. Preuss, Wilhelm von Humboldt, filosofía del lenguaje, magia, coras.

\section{Les éléments humboldtiens dans les théories de la religion et de la magie de Konrad Th. Preuss}

Cet article propose de considérer que les fondements philosophiques des théories de la religion et de la magie de l'ethnologue allemand Konrad Th. Preuss sont à rechercher dans la philosophie du langage de Wilhelm von Humboldt. Le but est de démontrer l'affinité de leurs pensées en comparant leurs méthodes respectives d'étude de la «culture intellectuelle». En analysant conjointement les notions de « façon de penser magico-religeuse » et les " représentations complexes », proposées par Preuss, ce texte établit leur rapport avec les théories humboldtiennes sur la formation de la parole et sur le rôle de la langue et du discours dans la constitution de la cosmovision.

Mots CLÉs : histoire de l'anthropologie, Konrad Th. Preuss, Wilhelm von Humboldt, philosophie du langage, magie, Coras.

On the affinities between Humboldt's philosophy of language and Konrad Th. Preuss' theories of magic and religion

This article deals with the affinities between the theory of magic and religion proposed by the German ethnologist Konrad Th. Preuss and Wilhelm von Humboldt's philosophy of language.

\footnotetext{
* Departamento de Filosofia, Universidad Autónoma Metropolitana, Iztapalapa, Instituto Nacional de Antropologia e Historia, Apartado Postal 7-1124, México, DF, CP 06700. E-mail : jnkpap@prodigy.net.mx.

Journal de la Société des Américanistes, 2002, 88 : p. 47 à 68. Copyright @ Société des Américanistes.
} 
Through a comparative exposition of their methods for the analysis of the "intellectual culture ", Preuss' theories are supplemented with a philosophical grounding. The relation between their thought is established through the analysis of Preussian concepts such as « magicreligious way of thinking " and " complex representations " and Humboldt's notions of the word-formation process, and the role of language and discourse in the constitution of a worldview.

KEY wORDs : history of anthropology, Konrad Th. Preuss, Wilhelm von Humboldt, philosophy of language, magic, Coras.

\section{La posición de Konrad Theodor Preuss en la historia de la antropología}

La comprensión de las formas de pensamiento y de las cosmovisiones indígenas americanas ha sido una preocupación constante en la antropología alemana, sobre todo en la Escuela de Berlín. En este contexto, Konrad Theodor Preuss (1869-1938), investigador del Museo Etnológico de Berlín y docente de la Universidad Humboldt (cf. Kutscher 1976 ; Schlenther 1959-1960 ; Westphal-Hellbusch 1969-1971), no sólo destaca por sus aportaciones a la documentación y sistematización de la vida religiosa indígena, sino que sobresale por haberse dedicado durante cuatro décadas con especial interés a la investigación de los fundamentos de la cultura intelectual de los pueblos americanos, en sus diferentes grados de civilización.

Las contribuciones que presentó en foros internacionales ponían de manifiesto su sólida formación en las tradiciones filológica y americanística de Berlín, su amplio conocimiento etnográfico, así como su tenaz búsqueda teórica, pues no dudaba en lanzar críticas irónicas contra muchas de las corrientes en boga (cf. Preuss 1914). Como asistente de Eduard Seler (1849-1922), Preuss se adentró en el campo de la mexicanística, tomando conocimiento del náhuatl y analizando comparativamente la iconografía presente en los manuscritos pictográficos y en los objetos arqueológicos, logrando interpretaciones que no raras veces contravenían la opinión de su maestro. Pero cuando, entre 1905 y 1907, Preuss realiza un extenso viaje de investigación por la región del Gran Nayar, encuentra en el registro etnográfico los elementos necesarios para formular una teoría sobre el " modo mágico de pensar », clave para la explicación de los fenómenos asociados a la religión, la magia y el ritual. Ésta se plasma en una serie de trabajos sobre las fiestas, cantos y oraciones rituales de coras, huicholes y mexicaneros (Preuss 1908, 1912, 1913, 1914, 1976).

Concretamente, lo que postula es que, para comprender las costumbres, la religión y las expresiones artísticas de los antiguos mexicanos y de los indígenas contemporáneos, es necesario buscar el modo de proceder de su intelecto, partiendo de las nociones nativas sobre el hombre y el entorno. Siguiendo este principio, Preuss concluyó que entre los pueblos naturales prevalece una concepción, según la cual, el mundo es una existencia plena de sustancia mágica. En contra de la opinión corriente, afirma que la creencia en la fuerza mágica no debe atribuirse a la deficiencia de las facultades intelectuales para razonar, ni a una emotividad desbordada, sino a un modo de percepción que es facilitador de « concepciones complejas ». Éstas son ideas sobre los objetos o seres mágicos plenos de una fuerza especial - desde piedras y flores hasta los pensamientos mismos - que se identifican con otros objetos mágicos, 
por la analogía con alguno de sus rasgos. En función del nudo analógico que los conecta, cada uno de estos se equipara con la totalidad de la potencia mágica que se extiende sin discontinuidades en el entorno. Las concepciones complejas se producen operando una « síntesis repentina » (Preuss 1913, p. 133) entre los meandros de la fantasía y la diversidad de impresiones sensoriales recibidas en el contexto mundano de la lucha por la supervivencia. Son posibilitadas por « el modo mágico de pensar », una forma particular de percepción. Por estar relacionadas directamente con la fuerza mágica que impregna la vida, las concepciones complejas son parte de la persona y la vinculan con el entorno.

Obviamente, en su tiempo, esta conceptualización del pensamiento indígena no fue apreciada cabalmente por los colegas que carecian, muchas veces, de la experiencia de campo, o que no fueron capaces de seguir a Preuss en su distanciamiento radical de los que consideraba prejuicios del hombre occidental. Más tarde, el desplazamiento de la investigación antropológica hacia tópicos propuestos desde tradiciones ajenas a la americanística de Berlín, por ejemplo el difusionismo de la Escuela Vienesa (cf. Schmidt et al. 1924) o el funcionalismo británico de corte utilitarista ( $c f$. Malinowski 1961 ; Radcliffe-Brown 1935, 1949, 1958), provocaron su salida abrupta de la memoria académica. Hoy, el lugar de Preuss en la historia de la antropología es incierto, circunstancia que enmarca la problemática de la elucidación de sus teorías de la religión y de la magia.

Durante su vida, Preuss sostuvo una franca polémica con los postulantes del animismo y, en particular con su autor; Edward B. Tylor (1832-1917). Sin embargo, los británicos simplemente ignoraron sus argumentos y lo asimilaron a la corriente del preanimismo liderada por el folclorista británico Robert R. Marett (1866-1943). Cuando, años más tarde, Marett pierde toda vigencia, las ideas de Preuss son fácilmente olvidadas, quedando así inconcluso el debate que había propuesto ( $c f$. Tylor 1977, Preuss 1894, 1904-1905 ; Marett 1979 ; Penniman 1965 ; Evans-Pritchard 1991 ; Alcocer 2000b). En contraste, algunos destacados antropólogos continentales como M. Leenhard (1876-1954) y J. P. B. Josselin de Jong (1886-1964) lo elogiaron e incluso retomaron algunas de sus ideas, hecho que empero, no atrajo mayor atención hacia su obra (cf. Leenhard 1997, p. 182 ; Effert 1992).

Las reacciones provocadas por Preuss en el seno de la Escuela Americanística de Berlín son diversas : hasta antes de su Expedición al Nayarit fue uno de los favoritos de Seler. Pero, tan pronto como invirtió la relación analítica entre el presente etnográfico y el pasado arqueológico, otorgando primacía al primero, la relación con su maestro se tornó distante y conflictiva (Preuss 1923 ; Jáuregui y Neurath s. f.).

Ahora bien, independientemente de que este conflicto pueda explicarse como la expresión del recelo de Seler frente a su alumno, por sentir amenazado su lugar protagónico en la escena americanista, existen entre los planteamientos de ambos una disimilitud crucial en la conceptualización del objeto, método y fin de la disciplina. Más allá de la relación analítica entre el presente y el pasado, en Seler no encontramos una formulación de la cultura intelectual como materia de estudio. Él se interesa por lograr un desciframiento de los manuscritos pictográficos lo más refinado posible para poder determinar así las situaciones étnicas e históricas prevalecientes durante la época prehispánica, mas no ve cómo esto podría modificar su propio concepto de civilización. Por otro lado, tampoco indaga qué procesos intelectuales dan lugar a la 
forma particular de la religión mexicana ( $c f$. Lehmann 1949, Westphal-Hellbusch 1969-1971, Nicholson 1973, Jáuregui y Neurath s. f.).

En cambio, para Preuss, más importante que poder desentrañar el significado de cada uno de los objetos arqueológicos y etnográficos o de cada una de las páginas de los manuscritos pictográficos, es lograr comprender el modo de proceder del intelecto que los crea, y el principio que los unifica, pues considera que el interés de estas investigaciones consiste en lo que puedan revelar acerca de la humanidad en general. (cf. Preuss 1913, 1914). Así, desde esta perspectiva, plantea que « uno de los puntos nodales para lograr una concepción uniforme de [la religión mexicana] es la lucha entre el sol y las estrellas », la « lucha cósmica » (Preuss 1905, p. 136 ; Neurath 1998, pp. 179-198, 1999, 2000).

La exigua continuidad del proyecto de Preuss se ha atribuido en gran medida a la merma general que sufrió la tradición etnológica alemana a consecuencia de la Segunda Guerra Mundial ( $c f$. Kutscher 1976, Fischer 1990), no obstante, es necesario reconocer que la originalidad de los planteamientos preussianos, que no alcanzaron a ser examinados, demanda repensar el ámbito en el que ha de inscribirse su elucidación.

\section{El giro antropológico de LA FILOSOFÍA CRÍtica}

Si se relega a un segundo plano la procedencia de los materiales etnográficos y arqueológicos con que trabajó Preuss, para abrir paso a la especificidad de su objeto de estudio y a las características que determinan su metodología, es posible reconocer la « tendencia de pensamiento » dentro de la cual desarrolla su proyecto. Se trata de la tradición iniciada por la filosofía crítica de Kant (1724-1804), que se pregunta por las condiciones de posibilidad del conocimiento humano, y que es continuada por el estudio filosófico de las lenguas, planteado por Wilhelm von Humboldt (1767-1835), teórico del clasicismo alemán, que reconoce en el lenguaje el órgano posibilitador del pensamiento ( $c f$. Cassirer 1993a, 1993b, 1997a ; Trabant 1986, 1990, 2000 ; Bunzl 1996 ; Di Cesare 1999).

Es bien conocido que la concepción del juicio sintético a priori nos ofrece la formulación más general del problema kantiano, pues a partir de ésta se determina la relación entre el saber y la realidad ( $c f$. Cassirer 1993a, p. 236). Kant definió el conocimiento como síntesis de una pluralidad dada en la intuición a través de las formas del entendimiento. La articulación de sus facultades, es decir; la síntesis entre la sensibilidad y el entendimiento, está a cargo de la fuerza imaginativa, de la que resulta la unidad del conocimiento con su objeto (Kant 1988, pp. 187-194). La fuerza imaginativa, en tanto que principio dinámico, es la causa del acto sintético, sin embargo, se mantiene como algo misterioso, "como la ciega pero indispensable función del alma ", respecto de la cual Kant se aventuraba a insinuar una " desconocida raíz común » (ibid., p. 117 ; cf. Trabant 1986, p. 18). Por otro lado, se sabe que esta tesis kantiana provocó bastante confusión en el contexto del incipiente romanticismo. Es la aportación de Wilhelm von Humboldt haber identificado al lenguaje con la «misteriosa raíz común» de las facultades del entendimiento, "llevando así el lenguaje de la periferia al centro de la reflexión filosófica » (Trabant 1990, p. 56 ; Di Cesare 1999, p. 28). 
La síntesis lingüística - necesariamente histórica y dialógica — define al lenguaje como ámbito donde tiene lugar el desarrollo dinámico de la vida intelectual, y que es asimismo su condición de posibilidad. Siguiendo a Kant, Humboldt establece la distinción radical entre el comienzo (temporal) y el surgimiento (trascendental) del lenguaje, determinando que sólo a la segunda cuestión corresponde una elucidación filosófica, y circunscribiendo la problemática diacrónica empírica al ámbito de la antropología, donde puede ser efectivamente abordada (Trabant 1990, p. 33 ; Di Cesare 1999, pp. 55-59).

Wilhelm von Humboldt es otro de los intelectuales cuyo programa de investigación no fue comprendido cabalmente, siendo, más bien, generalmente tergiversado ( $c f$. Trabant 1986, 1990, 2000 ; Borsche 1990; Di Cesare 1999). Su influencia sobre la escuela americanista y la antropología alemana es tangencial porque sólo se han retomado fragmentos de su proyecto ${ }^{1}$ ( $c f$. Trabant 1990, 1994 ; Müller-Vollmer 1994 ; Bunzl 1996 ; Di Cesare 1999, pp. 3-11), pero no se ha completado el programa del estudio filosófico de las lenguas ( $c f$. Humboldt 1990). Si se están indagando los elementos humboldtianos en la antropología y la filología de Konrad Theodor Preuss es porque hay una afinidad básica en la " tendencia de su pensamiento ", que puede rastrearse sobre la senda de su orientación kantiana compartida.

En efecto, tanto el proyecto de Humboldt como el de Preuss parten de la problematización crítica de la pregunta científica por el lenguaje y la cultura intelectual, oponiéndose a su objetualización. Así como la descomposición científica de las lenguas en listas de palabras y reglas gramaticales las despoja de su carácter esencial - vivo y dinámico - , así, el desmembramiento errático de la cultura intelectual de pueblos exóticos, arroja a nuestros pies un adefesio tan inverosímil, que cuesta trabajo pensar que por esta vía pueda alcanzarse la explicación del origen fáctico de la cultura, o reconstruirse su hipotética forma primitiva universal ( $c f$. Di Cesare 1999, pp. 21-22). Así, el reto que ambos enfrentan consiste en encontrar una manera de estudiarlas sin violentar por comodidad su esencia dinámica y sin hacer atribuciones infundadas a su complexión. Humboldt optó por afrontar las dificultades que la consideración de la dinámica del lenguaje comporta (ibídem) ; Preuss aceptó la fuerza mágica dando paso a la indagación de las condiciones de posibilidad de su desarrollo (Preuss 1894, p. 316, 1913, 1914, 1976 ; cf. Neurath y Jáuregui 1998).

De este modo, según la formulación humboldtiana, « la especificidad de la investigación antropológica consiste, en que suministra a los materiales empíricos un tratamiento especulativo y a los objetos históricos otro filosófico, abordando las condiciones reales de la humanidad en relación con sus desarrollos posibles » (Humboldt 1968, I [1795], p. 390, apud Trabant 1990, p. 52). Y, ¿qué otra cosa sino ésta hizo Preuss, cuando al ocuparse de problemas teóricos se aferra a la etnografía y al desenvolverse como investigador de campo retiene la perspectiva universal, haciendo importantes aportaciones a ambas ? (cf. Jungbluth 1933). Se entiende entonces cómo la orientación de esta crítica metodológica resulta productiva, pues hizo posible investigar cómo se articulan estos dos niveles en la práctica cotidiana del hablar e incluso en las concepciones complejas de los indígenas, para quienes pensar y hablar son las formas universales del acto mágico (Preuss 1913, p. 131, 1976).

Humboldt quería investigar los modos de proceder del intelecto humano, pero rechaza que esto pueda realizarse desde la abstracción de la filosofía. La actividad del 
intelecto humano es efímera y transcurriría sin dejar huella a no ser por el lenguaje, que se manifiesta siempre en el discurso dentro de la forma de una lengua particular. La lengua, en tanto que condición histórica del pensamiento, constituye la perspectiva abierta y, simultáneamente, determinada, en la que tiene lugar la formación del mundo (Di Cesare 1999, p. 53). La implicación antropológica de esta tesis consiste en reconocer que las ideas asociadas a la cultura de un grupo humano, la gran masa de pensamientos sobre el «mundo interior y exterior», no sólo vienen dadas en el lenguaje, sino que éste es su condición de posibilidad, es decir están siempre determinadas por una lengua particular ( $c f$. Humboldt 1994a, p. 24 ; Trabant 1990, p. 85).

La exigencia kantiana de objetividad y unidad rigurosa del saber, que resulta de esta nueva definición de su relación con el objeto, se alcanza atendiendo a la interrogante planteada por el modo en que el objeto se sujeta al conocimiento y por el modo como, de acuerdo con la variedad de los principios cognoscitivos, gana una variedad interna propia (Cassirer 1993a, p. 236). Según Humboldt, « la objetividad del concepto, en tanto que mediada lingüísticamente por el diálogo, es necesariamente intersubjetiva », al tiempo que su unidad rigurosa viene dada por la totalidad orgánica de la lengua, que necesariamente precede a sus partes (Di Cesare 1999, p. 53). En estos términos, cada lengua contiene una visión del mundo porque su organicidad peculiar; efecto de la actividad sintetizadora de la fuerza imaginativa, tiene como principio de su formación a la analogía.

«[La analogía] es el nexo que vincula a un objeto con los otros objetos y con el todo [...] es producida por la imaginación [...] se basa en la semejanza y reúne objetos diferentes, distantes unos de otros, individuando el rasgo que comparten. [De hecho], el pensamiento jamás trata a un objeto aisladamente, ni lo necesita en el todo de su realidad. Selecciona únicamente correspondencias, relaciones, y aspectos, y los pone en conexión » (Humboldt 1968, II [1798], pp. 129-138, III [1806], p. 170, apud Di Cesare 1999, p. 56).

Esta organización de la totalidad, siempre hipotética e inconclusa, realizada por la fuerza imaginativa, hace de la analogía, en tanto que principio de la formación lingüística del mundo, la primera aproximación cognoscitiva al mundo : « Unidad y totalidad son los dos conceptos que comprendemos bajo la expresión un mundo », fuera del cual nada puede ser pensado (Humboldt 1968, II [1798], p. 136, apud Di Cesare 1999, p. 56).

Si la posibilidad del conocimiento se basa en la unidad originaria del hombre con el mundo, hace falta la irrupción del lenguaje en esta unidad, para que se constituya por una parte el Yo y por otra parte el mundo. Sin este acto lingüístico que es el primer acto de reflexión, el hombre no puede contraponerse al mundo que lo rodea y a los objetos a los que parece vinculado, ni constituirse como sujeto ( $c f$. Humboldt 1990, p. 54 ; Di Cesare 1999, p. 32).

«Así pues, el lenguaje comienza inmediatamente y al mismo tiempo que el primer acto de reflexión; la palabra se halla presente en el mismo momento en que el hombre despierta a la autoconciencia desde el embotamiento del apetito en el que el sujeto devora al objeto ; se trata, por decirlo así, del primer estímulo que el hombre se da a sí mismo para detenerse de repente, mirar a su alrededor y orientarse » (Humboldt 1968, VII [1795-1796], p. 582, apud Di Cesare 1999, p. 33). 
En la medida en que el acto lingüístico es condición de posibilidad de la reflexión, la función del lenguaje no puede reducirse a la comunicación. La mediación del lenguaje entre el Yo y el mundo no se limita pues a ponerlos en relación. Más bien implica el quebranto de su unidad originaria - fundamento de la posibilidad del conocimiento - , determinando su constitución. Porque hombre y mundo se constituyen en el lenguaje, « uno y otro están ya dados siempre en el horizonte de [éste] [...] Creer que se puede trascender la experiencia lingüística para adquirir un punto de vista exterior significa conservar una concepción instrumental del lenguaje » (Di Cesare 1999, pp. 34-35). Sin embargo, aceptar la tesis humboldtiana relativa a la constitución del hombre y el mundo en el lenguaje implica sustituir la perspectiva genética sobre el origen del lenguaje por otra trascendental.

En un argumento análogo, Preuss plantea que el momento teórico del surgimiento de la humanidad se caracteriza por el desarrollo autónomo del intelecto que « consiste en levantarse por encima de la actuación conforme al instinto, e implica un intento de comprender las cosas que impresionan los sentidos según conceptos particulares, así como de dominarlos » (Preuss 1914, pp. 8-9).

Para superar el solipsismo derivado de estas tesis, Wilhelm von Humboldt examinó cómo opera la fuerza imaginativa en el ámbito del lenguaje, es decir, ¿cómo produce el lenguaje el concepto? - indagación que lo llevó a superar el esquematismo kantiano y a sustituir el modelo monológico del conocimiento por otro dialógico. En efecto, porque « todo hablar se basa en el diálogo » (Humboldt 1994b, p. 164 ; Di Cesare 1999, p. 39), sólo la relación sujeto-sujeto satisface, en última instancia, la doble exigencia del conocimiento de objetividad y de unidad rigurosa. El hombre sólo puede acercarse a la «totalidad de lo cognoscible » por la vía subjetiva (Humboldt 1994a, p. 28), pero «la objetivación sólo aparece cumplida cuando el Yo puede percibir su propia representación objetivada fuera de sí mismo, lo que ocurre cuando el Tú, en un acto de reciprocidad, le devuelve al Yo su propia palabra como palabra de otro » (cf. Humboldt 1990, pp. 74-89 ; Di Cesare 1999, pp. 35-40).

En un primer momento « la actividad de los sentidos y la del entendimiento se combinan sintéticamente para seleccionar de la multiplicidad de las impresiones sensibles que acceden al sujeto, los rasgos, los aspectos que caracterizan para este último al objeto, y unificarlos » produciendo una forma subjetiva de ver el objeto : « el hombre vive con los objetos de la manera como se los presenta el lenguaje » (Humboldt 1990, pp. 74, 83). Sin embargo, esta "representación subjetiva » no es el concepto, pues no ha sido objetivada por la mediación del lenguaje. Para esto es necesario que intervenga el sonido, pues « la representación adquiere existencia sólo en la forma sensible de la palabra en la que es fijada. [...] Este proceso, la fijación, es simultáneo y sucede en el mismo acto sintético, y es incluso condición del mismo » (Di Cesare 1999, p. 37).

Según Humboldt, esta disposición originaria de la naturaleza humana, donde la idea, los órganos de la fonación y el oído guardan con el lenguaje una unión indisoluble, no es susceptible ya de ulterior explicación. Lo que interesa destacar es cómo la nítida resonancia del sonido, igual que el repentino impulso sintético de la idea, se proyecta como una totalidad que se apodera del ánimo entero. La eficacia del sonido « reposa sobre el hecho de que el oído percibe una sensación de movimiento 
[...] una verdadera acción [...] que procede del interior de un ser vivo » (Humboldt 1990 , p. 75).

Esta explicación de la eficacia del sonido establece un elocuente paralelismo con la concepción cora, reconocida por Preuss (1912, 1913, 1914, 1976), que atribuye poderes mágicos a los mismos pensamientos y las palabras. Según los coras, los pensamientos y las palabras son la base para cualquier acto mágico. De hecho, por sí solos implican acciones. Sólo el pensamiento y la palabra gozan de semejante universalidad. Lo más interesante es que, según esta concepción, " no solamente los seres humanos hablan, también los sonidos de los instrumentos musicales son " palabras ”, los animales cantan, hablan y lloran ; flores y animales gritan, y algunos instrumentos ceremoniales se manifiestan en el hecho de que " hablan " (Preuss 1913, p. 131, 1976, p. 21). Sus palabras y sus pensamientos nunca pueden ocurrir en un monólogo, porque resultan de manera inmediata en su realización misma. Su mero proferimiento basta para recrear el mundo. Pero, precisamente porque son absolutamente efectivos, entre los coras la obtención de pensamientos correctos es fuente constante de preocupación. «Sin el pensamiento adecuado, las acciones no pueden tener éxito alguno, [por eso] lo más importante, lo verdaderamente mágico, es la iluminación repentina, la comprensión súbita de la manera en que debe hacerse tal o cual cosa. La realización misma, entonces ya no importa tanto » (Preuss 1913, pp. 129, 133).

Se aprecia claramente cómo esta concepción indígena de la cultura intelectual se acerca a los planteamientos humboldtianos, que al desistir del intento de identificar al agente productor de sentido con alguno de los términos del dualismo cuerpo-alma, abren paso a una concepción de la lengua como enérgeia ${ }^{2}$, evitando recaer en la penosa conclusión según la cual cada vez que se habla ocurre una suerte de « transubstanciación » entre la immaterialidad del sentido del habla y su expresión material mediante sonidos (Cassirer 1993b, p. 337). Frente al dilema que obliga a pronunciarse por la concepción estética o por la concepción semiótica del lenguaje, Humboldt construye una posición intermedia, que sitúa a la palabra entre la imagen (o símbolo) y el signo, sin ser ni lo uno ni lo otro (Humboldt 1990, pp. 74, 91, 131 ; 1994a, pp. 13, 29 ; 1968, V [1824-1826], pp. 428-429 ; VII [1795-1796], pp. 581, apud Di Cesare 1999, pp. 41-46) :

« Si en el signo lo designado posee una existencia autónoma respecto del signo, en el símbolo es el símbolo mismo quien la posee respecto de lo simbolizado; si en el primero prevalece el elemento espiritual, la espontaneidad, en el segundo domina el elemento material, la receptividad. En la palabra, sonido y concepto, que no consienten separación alguna y son incompletos cada uno por sí mismo, forman una unidad y constituyen una única esencia » (Di Cesare 1999, p. 43)

Ahora contamos con los elementos para comprender por qué Humboldt parte del rechazo a las teorías que ven en el lenguaje una herramienta cuya función fuera meramente mnémica y comunicativa :

« La limitada idea de que el lenguaje ha surgido mediante la convención y de que la palabra no es nada más que signo de una cosa que existe con independencia de ella o de un concepto de igual condición ha ejercido la más perniciosa influencia sobre el tratamiento interesante del estudio del lenguaje » (Humboldt 1968, III [1806], p. 167, apud Di Cesare 1999, p. 30). 
La síntesis en el lenguaje comporta una fuerza creadora, siempre en movimiento, que es también fuerza creativa y cognitiva. Ésta, en su desarrollo dinámico, tiende a la creación de la diversidad en una permanente tensión entre la tendencia dictada por su carácter y los límites marcados por su estructura, de una parte, y la libertad de cada hombre para, rondando sus límites, forzarlos a dar de sí ( $c f$. Humboldt 1990 ; Trabant 1986, 1990 ; Di Cesare 1999).

\section{LAS CONCEPCIONES COMPLEJAS}

Basta leer las primeras líneas del prólogo a Die Nayarit-Expedition para percatarse de que el destino con que Preuss quiso impregnar su obra es muy semejante a la intención de las investigaciones de Wilhelm von Humboldt. Se trata de « transmitir la comprensión profunda de la cultura intelectual de algunas tribus del mosaico cultural mexicano », publicando "los grandes tesoros del pensamiento autóctono que aún viven en los textos de mitos, oraciones y cantos religiosos, por él " rescatados " de la extinción a manos de la civilización occidental ». Documentos que considera, de una parte, un « legado sagrado » y un "monumento a los indígenas nayaritas » y de la otra, una exhortación a las ciencias filológicas e históricas, a que agucen su conciencia ante la necesidad inminente de promover su recuperación (Preuss 1912, p. III, 1976, pp. 19-21).

Desde sus primeras investigaciones, Preuss reconoce el valor que subyace a la diversidad cultural y afirma que el estudio de la cultura intelectual de los pueblos naturales ${ }^{3}$ es en sí valioso, no porque a partir de éste pueda reconstruirse la prehistoria de la humanidad, sino por lo que pueda enseñarnos de la humanidad contemporánea. Siguiendo la tradición iniciada por Kant y continuada por Wilhelm von Humboldt, le interesa indagar cuáles son las condiciones de posibilidad del desarrollo de la cultura intelectual de la humanidad en general, así como la diversidad de principios que en cada caso concreto lo unifican ( $c f$. Preuss 1914).

Las investigaciones de Preuss parten de la crítica metodológica de las teorías positivistas (animismo, difusionismo, evolucionismo) que, basándose en la comparación de datos descontextualizados violentan la complejidad de los fenómenos, para conformarse con burdas « explicaciones » causales. Además, es certera al enfatizar que, « quienes tienen una concepción desarrollista ${ }^{4}$ no valoran adecuadamente que logros como la comprensión intelectual del entorno o la formación del lenguaje, implican ya el desenvolvimiento exitoso de todas las facultades mentales y psíquicas que encontramos también entre nosotros » (ibid., p. 4). La universalidad de estas facultades intelectuales - que han caracterizado al hombre desde el punto cero de la cultura - es pues la condición de posibilidad del surgimiento de la cultura, manifestada siempre a través de formaciones particulares.

" Para no errar desde el principio y para no plantear algo completamente inverosímil, nuestra investigación no debe proyectarse con la única finalidad de encontrar siempre la primera forma de todos los fenómenos en cuestión. Más bien, deben indagarse los fundamentos de las condiciones intelectuales de antaño en contraste con las modernas, así como su relación con las fuerzas intelectuales activas y permanentes de la humanidad » (ibid., p. 5) 
Bajo esta óptica, redefine los objetivos que las investigaciones históricas pueden perseguir, desplazando con ello su problemática, tratada generalmente de manera dogmática, al terreno empírico, donde puede ser efectivamente estudiada :

« La única meta digna que la etnología debe plantearse con respecto a las relaciones históricas, consiste en investigarlas dentro de un área reducida, donde resulte posible demostrar las migraciones con seguridad. Me refiero a regiones donde existe un parentesco lingüístico concreto o tal acumulación de patrimonio cultural compartido, que cualquier duda pueda excluirse de antemano. Por lo demás, primero deberían definirse las particularidades de las áreas mayores, en lugar de dar demasiada importancia a semejanzas muy particulares como indicios de acontecimientos históricos » (ibid., p. 7).

Esta delimitación del campo de estudios empíricos enfrentó a Preuss con una problemática equivalente a aquella encarada por Humboldt cuando decide apartarse de la tradición de estudios gramaticales, que analiza las lenguas más diversas teniendo siempre a las lenguas clásicas como canon. La gran innovación humboldtiana plantea que toda lengua es susceptible de ser analizada a partir de sí misma, " comparando su forma (lingüística) con un itinerario peculiar por vía del cual la actividad formadora, junto con la fuerza [imaginativa] que está a su base y con la que en definitiva se identifica, ha de canalizarse para poder operar » (Di Cesare 1999, p. 67 ; Humboldt 1990, p. 67).

En este mismo sentido, Preuss señala que « cualquier reconstrucción del hombre natural según los modelos del hombre moderno es por fuerza improcedente ». De forma que, para hablar de la cultura intelectual de los pueblos naturales, " estamos obligados a deshacernos de todas nuestras concepciones religiosas, morales y científicas, y nos tenemos que imaginar despojados de todos nuestros placeres estéticos acostumbrados ", porque, en definitiva, de lo que se trata es de acceder al modo de proceder de su intelecto (Preuss 1914, p. 1).

Entre los primeros fenómenos psíquicos que Preuss reconoce a partir de sus estudios sobre el arte de los Orang Semang de Malasia, está el papel central que la imaginación desempeña en la formación de las concepciones complejas o mágicas de los aborígenes sobre sí mismos y sobre el entorno (cf. Preuss 1899). Según Preuss, se trata de una facultad que actúa como una fuerza intelectual productora de nociones formadas por síntesis repentinas que combinan impresiones sensoriales con ideas fantásticas. Este proceso, que implica apartarse del instinto y abrir paso a una comprensión del mundo según conceptos particulares que puedan dominarlo, cuestión nunca garantizada de antemano, no siempre reporta una ventaja a la supervivencia del hombre. No obstante, Preuss le confiere gran importancia, pues es en realidad, « el primer brote de todo lo grande y sublime de la religión y de la ciencia, [...] un proceso por el cual, aun los objetos más alejados del mundo son introducidos paulatinamente en el razonamiento humano " (Preuss 1914, pp. 8-9).

Según Preuss, la libertad creadora otorgada al hombre por la fuerza imaginativa de su intelecto no capta las cosas del mundo en su plena individualidad. Más bien, opera distinguiendo de la totalidad, en primera instancia, aquellos objetos que parecen tener una relación inmediata con la procuración del sustento vital y con el destino del hombre pues, como ya señalaba Humboldt, éste sólo puede acercarse a la « totalidad de lo cognoscible » por la vía subjetiva (Humboldt 1994a, p. 28). 
A este proceso, que distingue de la unidad indiferenciada del mundo sólo las cosas que llaman su interés, y que introduce en sus razonamientos toda clase de apariencias exteriores e ideas fantásticas, insertándolas mediante un acto sintético producto de su fuerza imaginativa, en la red analógica que conforma su visión del mundo, Preuss lo denominó « modo mágico de pensar » (Preuss 1912, 1913, 1914, cf. 1976, pp. 22, 23, $26,27)$.

Porque la fuerza imaginativa es condición de posibilidad del idealismo ${ }^{5}$, en la teoría del etnólogo berlinés, la magia no puede caracterizarse como « ciencia falsa » (cf. Wittgenstein 1997, p. 21) sólo porque no satisface los fines utilitaristas que la ideología positivista asigna al conocimiento. Preuss define el idealismo como « procurar el sustento mediante razonamientos equivocados y haciendo uso de medios igualmente equivocados » (Preuss 1914, p. 10), para enfatizar que la liberación del instinto tiene una importancia mayor que la aplicación del razonamiento para la vida práctica ${ }^{6}$.

Sin un entendimiento de la forma concreta que adopta el proceso sintético creador de las concepciones complejas, « [...] será incomprensible cómo, por ejemplo, un dios puede hacer su aparición en la tierra sin dejar de existir como estrella en el cielo y cómo puede revelarse en las cosas más diversas al mismo tiempo » (Preuss 1912, p. LIII). Pero, «debido a que las ideas mágicas pueden asociarse con todas las acciones humanas, aun cuando éstas no sean más que simples movimientos expresivos, y porque asimismo pueden insertarse arbitrariamente en cualquier punto del desarrollo de las concepciones sobre el entorno, e inclusive influirlo, emergen formaciones realmente complejas » (Preuss 1914, p. 8).

Este proceso actúa erráticamente, pero sigue un impulso creador que las unifica conectándolas en una red analógica que, en cuanto totalidad, siempre las precede. Así, comprender las concepciones complejas consiste en reconstruir esta complicada serie de asociaciones mitológicas, que son la historia mágica de las cosas. Desde luego, dice Preuss, « ... en muchos casos los puntos de comparación que explican las identificaciones mágicas ya no pueden reconstruirse. Sin embargo, puede afirmarse con certeza que siempre deben haber existido algunos » (ibídem, p. 14).

\section{LA ESCRITURA MÁGICA PICTÓRICA}

Preuss inició sus investigaciones etnológicas manejando una inmensa cantidad de materiales empíricos. Primero provenientes de las colecciones albergadas en los museos etnográficos y, sólo años más tarde, directamente entre los indígenas americanos, en el Occidente de México (1905-1907) y en Colombia (1914-1919), logrando articular, como pocos antropólogos, su quehacer como trabajador de campo con su desarrollo como teórico de la religión y de la magia. Por eso, al tratar de este último, no es conveniente desligarlo de los estudios concretos sobre los cuales tomaron forma sus teorías.

Durante sus primeros años como ayudante científico de la sección de Oceanía y África del Museo Etnológico de Berlín, Preuss se ocupó en investigaciones sobre el arte del río Sepik de Nueva Guinea, entonces Kaiser-Wilhelms-Land y del de los Orang Semang de las selvas en el interior de la península de Malaka (Malasia). De estos años, concretamente de 1899, proviene un interesante artículo sobre la escritura 
mágica pictórica de los Orang Semang, que nos permite ejemplificar cómo comenzó Preuss su teorización referente a las concepciones complejas. Se trata de una investigación sobre las peinetas de la colección Hrolf Vaughan Stevens, que busca comprender el sistema de escritura pictográfica a través de su relación con las concepciones aborígenes sobre la enfermedad, su curación y la fuerza mágica.

Este estudio, parte de la distinción de tres tipos de diseños artísticos - el ornamental, el mnemotécnico y el mágico - y demuestra que la repetición de los diseños mágicos tiende, por la paulatina sofisticación de los mismos, a oscurecer su significado, haciéndolos pasar ante los ojos del investigador poco cauto, por ornamentales, pero sin que esto implique que el objeto como totalidad pierda su eficacia mágica. Las peinetas en cuestión son portadas por las mujeres de la tribu, con la finalidad de ahuyentar a las enfermedades que, viajando sobre el viento, les son enviadas por Keiî, el dios del trueno, como castigo por sus malas acciones. Ahora bien,

« Es un hecho conocido que al primitivo, todo aquello que de alguna manera pertenece a su cuerpo o que ha tenido contacto con él, no le puede dejar sin cuidado. Prefiere quedarse con estas cosas porque las considera parte de sí mismo. A estas partes les podría pasar algo que tuviera repercusiones sobre sí mismo. Cabellos, uñas, excrementos, ropa, restos de comida, inclusive sus huellas pertenecen a esta clase de fenómenos. La contraparte a esto es el hecho de que una parte tome el lugar de la totalidad. Las plumas de un ave tienen el mismo poder mágico que el animal completo o la especie completa. Escupir una hoja de coca masticada o colgar un pedazo de ropa en un "árbol de trapos" son ofrendas que implican la acción del hombre completo sobre la divinidad que habita en estos lugares » (Preuss 1914, p. 10).

Preuss se percata de que todos los diseños integran la representación de una flor con la de una parte del cuerpo. Las enfermedades quieren afectar a las mujeres a través de su cabello. Los diseños florales de las peinetas las alejan con su « olor », permitiendo a las mujeres seguir su camino. Las representaciones corporales hacen referencia a la parte o partes que, efectivamente, pueden verse afectadas por cada enfermedad particular, contra la cual el « olor» de la flor en cuestión tiene la fuerza mágica para actuar. Siguiendo este razonamiento, Preuss identifica 140 diseños diferentes, destinados a combatir 70 enfermedades.

Pero ¿podemos saber cómo se establecieron las asociaciones entre flores, partes del cuerpo y enfermedades? Preuss logra comprender que lo que las vincula es el nexo establecido entre éstas por analogía operada por la actividad sintetizadora de la imaginación. La fuerza imaginativa "conecta lo similar con lo similar e introduce entre lo que carece de similitud términos intermedios que establezcan la conexión », presentándolos en una unidad indivisa y en un todo organizado. (Humboldt 1968, II [1798], p. 138, apud Di Cesare 1999, p. 56). En el caso de las peinetas, la conexión entre flores y enfermedades viene dada por la estación del año en que enfermedades y flores se manifiestan, información no contenida directamente en los diseños, pero que indica su comprensión y vínculo con el entorno. La parte del cuerpo alude también a la totalidad de la persona. De manera que las mujeres portan sus peinetas como remedios medicinales. Claro está que « ellas no se conforman con su utilidad " inmediata " y buscan elaborarlas cada vez con más arte ». La sofisticación resultante produce que los significados concretos de cada uno de los motivos que integran los diseños se olviden ; sin embargo, afirma Preuss, los objetos no pierden su atributo de fuerza mágica (cf. Preuss 1899). 
Si se concibiera el lenguaje o código de estas peinetas tan sólo como un medio de comunicación de significados, tan pronto como los conocimientos para descifrarlos se perdieran, la eficacia mágica de los mismos tendrían que verse mermada. Sin embargo, Preuss constata el fenómeno contrario, y en analogía con la concepción humboldtiana acerca del carácter sintético del proceso de formación de palabras, las cuales tienen un carácter sígnico y otro imaginario, reconoce que, para comprender qué posibilita la eficacia mágica de estos objetos, es necesario estudiarlos en su unidad, desde la perspectiva de las « tres formas simbólicas » que sintetizan, a saber, arte, mito y lenguaje (cf. Preuss 1899 ; Cassirer 1996, 1997a, 1997b, 1997c).

\section{LA MAGIA EN LAS PALABRAS}

Durante los años comprendidos entre su incorporación a las investigaciones americanísticas y la expedición al Nayarit, Preuss logró formular, si es lícito llamarles así, los principios estructurales que organizan las concepciones mágico-religiosas de los pueblos del círculo cultural mexicano ; la forma formata y la forma formans de la religión astral mexicana, compartida por los mexicas y los indígenas del Occidente de México (cf. Preuss 1905; Neurath 1999 ; Di Cesare 1999, pp. 77-84). Pero no fue sino hasta que trabajó directamente con los textos rituales de los coras, los huicholes y los mexicaneros, que se percató de la importancia del discurso, es decir, de la eficacia mágica implicada en acciones como pensar, narrar mitos, proferir oraciones e interpretar cantos rituales.

De su experiencia entre los indígenas del Gran Nayar, le sorprende ver corroborados sus planteamientos relativos a la religión mexicana. En particular, la idea de que la lucha cósmica es un principio unificador que permite explicar la gran cantidad y diversidad de hechos y concepciones que se presentan al investigador (Preuss 1905; Neurath 1999). Adicionalmente, su expedición a Nayarit también comprende el descubrimiento del modo mágico de pensar y su postulación teórica como principio que permite suministrar una explicación uniforme del proceso implicado en la producción de hechos y concepciones mágicas (Preuss 1912, 1913).

Este énfasis en la importancia del modo de pensar permite vislumbrar una afinidad con los intereses de Wilhelm von Humboldt. Sin embargo, para postular la presencia de elementos humboldtianos en las teorías de la religión y de la magia de Preuss, es necesario indagar si el modo mágico de pensar satisface la exigencia kantiana de la objetividad y unidad rigurosa del saber, que se plantea a partir de su definición de la relación del saber con el objeto.

Humboldt sustituye el modelo monológico del conocimiento (sujeto-objeto), por otro dialógico (sujeto-sujeto). De modo que, en la formación, siempre subjetiva, de un objeto, pueden distinguirse dos fases. La primera consiste en la síntesis de la pluralidad dada en la intuición a través de las formas del entendimiento, que es motivada por la fuerza imaginativa, y en la simultánea transposición (del interior al exterior) de la forma subjetiva de ver el objeto por la mediación del lenguaje. En la segunda fase, el proceso de objetivación se caracteriza por la intersubjetividad y la reciprocidad, donde se recibe la propia palabra como palabra de otro. Ésta se introduce en la organicidad de la lengua por medio de la analogía. «La formación del mundo se revela un proceso ininterrumpido de unificación, consistente en convertir la masa 
ingente de los fenómenos aislados e inconexos en una unidad indivisa y en un todo organizado » (Humboldt 1968, II [1798] :129, apud Di Cesare 1999, p. 56).

En el planteamiento de Preuss (1914), el hombre no percibe en primer lugar los objetos del mundo en su individualidad sino que percibe una totalidad indiferenciada y continua. La exposición a una prolongada tensión psíquica, producida por las penurias de la lucha por la supervivencia, estimulan su intelecto. Éste posa su atención sobre aquellos objetos que aparentan un vínculo directo con su propia subsistencia. Así, éstos son introducidos a su intelecto seleccionando, por analogía, los rasgos que los conectan a otros objetos similares, integrándolos a la totalidad organizada. Este proceso está a cargo de la fuerza imaginativa que de manera repentina opera una síntesis que introduce al objeto en el intelecto insertándolo en algún punto de la red analógica que unifica su visión del mundo.

Hasta aquí, los planteamientos de Humboldt y Preuss se corresponden. Sin embargo, Preuss no problematiza cómo tiene lugar la transposición de la representación subjetiva del interior al exterior, tampoco aclara cómo ésta adquiere existencia, ni bajo qué forma sensible es fijada. En lugar de eso ofrece algunas reflexiones en torno a la concepción cora que atribuye poderes mágicos a los pensamientos. Sobra decir que él no pone en duda la plena realidad que las concepciones complejas sobre sí mismo y sobre el entorno tienen para los hombres naturales. No obstante, la centralidad que Preuss confiere a la forma del proceso creador de concepciones complejas, ofrece la clave para formular una posible explicación de la transposición y la fijación a partir de los propios elementos que encontramos en su obra.

Desde la perspectiva cora, la transposición y la fijación de la representación subjetiva se produce automáticamente en virtud de dos hechos, que en sí mismos se ajustan a la definición del proceso de producción de concepciones complejas, a saber : a) la identificación de los pensamientos con las palabras y b) la fuerza mágica de los pensamientos que instantáneamente los realiza. En comparación con las tesis de Humboldt, en este proceso el papel mediador de la palabra no está siempre presente. En uno de los ejemplos seleccionados por Preuss, « Nuestro hermano mayor sale en el oriente y mata a la serpiente acuática del poniente con un flechazo. Si no actuara así, el mundo se inundaría, pero ahora trata de recuperar su flecha [...]. Nuestro hermano mayor sabe cómo actuar. ¿Acaso no recupera su flecha con la fuerza de sus pensamientos? La tiene mientras permanece allá, al otro lado del mundo » (Preuss 1913, p. 130].

Los pensamientos de esta deidad cora prescinden de la mediación lingüística y se transponen instantáneamente en virtud de su fuerza mágica verificando un acto : la recuperación de las flechas. En otro ejemplo, « se objetivan los pensamientos de la chicharra, [...] se convierten en las flores de los árboles frutales que ella misma trajo del cielo. Ella dice: "Aquí les daré mis pensamientos ". Pero se refiere a los frutos » (Preuss 1913, p. 130).

Igualmente eficaz es el pensamiento de los dirigentes de los rituales y de aquellos que « tienen » una manda para obtener favores personales, con el Santo Entierro, por ejemplo. Los pensadores, como también se llama a los chamanes y algunos ancianos, se someten a duras prácticas de autosacrificio con la finalidad de condensar en sí fuerza mágica y obtener pensamientos correctos para la celebración exitosa del ritual (cf. Neurath 1998, 2000). Según la concepción cora, «lo más importante para la 
fuerza mágica, lo verdaderamente mágico, es la iluminación repentina y espontánea, la comprensión súbita de la manera en que debe hacerse tal o cual cosa. La realización misma, entonces, ya no importa tanto ", porque, como vimos, está ya implicada en la acción (Preuss 1913, p. 133). Al respecto cabe destacar que, durante las fases de vigilia, ayuno y oración, se ha de evitar a toda costa que los pensadores se enojen (Valdovinos, comunicación personal), pues las consecuencias de este tipo de pensamientos en combinación con la fuerza mágica, podrían ser fatales. Por otro lado, entre los indigenas que han hecho alguna manda para la obtención de favores personales, uno de los votos más duros de cumplir es el de la abstinencia sexual. En la manda con el Santo Entierro, la transgresión de esta prohibición trae casi irremediablemente la muerte, como lo explicó Anita de Jesús, cora de Jesús María Chuisete'e. Así, algunas personas prefieren encerrarse a " piedra y lodo » pues el simple hecho de concebir un pensamiento erótico sería tan grave como su realización.

De los casos, donde la transposición tiene lugar prescindiendo de la fijación, puede decirse que la manera subjetiva de ver el objeto deviene objetiva en la medida en que se recurre a la propia creencia indígena que atribuye eficacia inmediata a los pensamientos, y que por lo tanto no satisface la doble exigencia kantiana. No obstante, no debe pasarse por alto que en los casos donde es necesario «buscar» el pensamiento que está provocando alguna enfermedad, por ejemplo, los chamanes no fallan en encontrarles bajo la forma de piedras o sustancias en descomposición, o sobre las flechas de brujería, que los portan como inscripción. Además, la verificación de estos procesos tiene lugar generalmente en el contexto de un ritual, donde las representaciones se encuentran fijadas por la mediación de las palabras de los chamanes y otros actores rituales, que son los dioses, y de su parafernalia ritual, plena también de la fuerza mágica que es transmitida mediante su « voz ».

Se ha dicho, con Humboldt, que la representación subjetiva, para alcanzar la existencia, requiere ser fijada bajo la forma sensible del sonido. También se ha dicho que, aunque esta disposición originaria de la naturaleza humana no sea susceptible de ulterior explicación, el sonido se distingue de otras formas sensibles porque se proyecta como una totalidad y es percibida por el oído como una sensación de movimiento, una acción que emana del interior de un ser animado. Entonces, de acuerdo con esta caracterización, puede afirmarse que, en ciertos contextos rituales en lugar de seres antropomorfos, es la parafernalia ritual de los dioses la que satisface la exigencia de ver mediadas sus representaciones subjetivas por vía de la palabra.

"No solamente los seres humanos hablan, también los sonidos de los instrumentos musicales son " palabras", los animales cantan, hablan y lloran ; flores y animales gritan. La eficacia de algunos instrumentos ceremoniales se manifiesta en el hecho de que "hablan ": El lucero hablará con sus palabras, con sus plumas, con su humo de tabaco. También ellos [los dioses de la lluvia] hablan a través de sus varas emplumadas » (Preuss 1913, p. 131).

Pero ¿qué tan lejos va Preuss en la aceptación de la concepción cora que atribuye fuerza mágica a los pensamientos ? y ¿qué postura toma frente a su identificación con las palabras? Es su opinión que, en el contexto de los cantos rituales « el hablar no debe ponerse en el mismo plano que el pensamiento, ya que [el primero] se refiere a una expresión [más] de la práctica mágica : " palabras ", dice, debe entenderse en sentido 
figurado ». Asimismo, afirma que « aparte del pensar existen otras acciones mágicas, como son, por ejemplo, el cantar, el danzar y el fumar tabaco » (ibid.).

Si se toma al pie de la letra este señalamiento sobre las «palabras », destaca su afinidad con la caracterización humboldtiana de la lengua, « que es al mismo tiempo imagen y signo ", forma formata y forma formans (Humboldt 1968, V [1824-1826], p. 428, apud Di Cesare 1999, pp. 42,68). Sobre todo cuando la razón para negarles el mismo estatuto que al pensamiento yace en que se trata de una entre varias expresiones de la práctica mágica y no porque se las conciba de manera instrumentalista. Por otro lado, ¿quién puede negar que la práctica ritual, en tanto que enérgeia, logra transponer y fijar una representación subjetiva del mundo devolviendósela a los participantes como algo dado y anterior, pero simultáneamente, siempre susceptible de ser modificada mediante síntesis renovadas ? (cf. Di Cesare 1999, pp. 63-71).

Las concepciones complejas, en tanto que forma de proceder del intelecto, son la condición de posibilidad del acto mágico, mas no lo implican necesariamente. Sólo cuando un objeto causa interés mágico adquiere de manera repentina un lugar en las series de complejas identificaciones y asociaciones mágicas. Integrándose a la totalidad de la potencia mágica expandida por el mundo en virtud de la unificación operada por la analogía, se manifiesta como forma y como materia.

« La forma sólo se puede aprehender en una materia, mientras que la materia accede a la cognoscibilidad únicamente en tanto que posee una forma. [...] materia y forma se configuran como conceptos relacionales aptos para gobernar un proceso ininterrumpido en el que nada está destinado a restar simplemente forma y nada está destinado a restar simplemente materia » (ibid., p. 65)

Según Preuss, esta dinámica se encuentra en la base de la concepción indígena sobre la eficacia de los seres personales y del contexto en el que ocurren los procesos que percibe con sus sentidos. Además aclara por qué ésta no puede explicarse a partir de la idea de causalidad. Los hechos dispuestos en una secuencia no se encadenan presuponiendo una causalidad. Más bien la totalidad de la secuencia forma una entidad autónoma, susceptible de ser repetida por un acto mágico y con el mismo efecto. « No es el post hoc ergo propter hoc lo que inspira al primitivo. Éste se contenta con el ser complejo de todos los fenómenos. La manera en la cual ocurre un fenómeno, lo plástico, lo que describe el proceso es para él lo más importante » (Preuss 1914, p. 15).

Ernst Cassirer (1874-1945), retoma la propuesta de Preuss para esta discusión, argumentando que el modo mágico de pensar se distingue del concepto científico de causalidad porque no quebranta ni interrumpe la contigüidad de los elementos de la experiencia (Cassirer 1997b, pp. 50-62). Esta breve reflexión no agota la problemática relativa a la noción de causalidad en el modo mágico de pensar. No obstante, señala la vía por donde ha de buscarse el fundamento de la concepción que no caracteriza a los procesos, espacios y objetos rituales como representaciones de entidades mágicas, las cuales existirían en otro plano ontológico, y que más bien, atribuye a todas sus réplicas la cualidad de ser ellas mismas la cosa que figuran (Alcocer 2000a, 2000b).

La concepción cora que atribuye fuerza mágica a los pensamientos, y que por lo tanto les atribuye una potencia creativa que se realiza en el mismo acto de su enunciación, permite retomar ahora la segunda fase del proceso sintético de objetiva- 
ción del modo subjetivo de ver el mundo propuesto por Humboldt. Se trata de indagar si en la teoría de la magia de Preuss hay lugar para la intersubjetividad y la reciprocidad que permiten considerar acabada la síntesis. En efecto, el etnólogo considera a « los testimonios textuales de la literatura oral como la fuente más segura acerca de la vida intelectual de estos indígenas » (cf. Preuss 1998 [1908a], p. $261 ; 1998$ [1908b], p. 265 ; Neurath y Jáuregui 1998, p. 28). Pero, ahora la cuestión que ha de indagarse consiste en saber cómo los textos de la literatura oral desempeñan un papel en la objetivación del mundo.

El corpus literario, en tanto que materialización de la red de analogías entretejidas en cuya organicidad se conforma la unidad del mundo, es por fuerza anterior a la persona. Así, al hablar de la reciprocidad implicada en la objetivación de una cosmovisión debe subrayarse ante todo que los textos de este corpus no pueden tenerse como propiedad. Entre los coras, el «costumbre » es el regalo que hizo Hatsikan, el lucero de la mañana, a los hombres para que con ellos procuraran su bienestar. En sentido más amplio, son el legado de todos los ancestros. Ya por eso, los hombres están obligados a devolverles este don a través de las mismas fiestas. Así, la objetividad de su eficacia mágica viene dada por su antigüedad y por su repetición.

Por otro lado, la temática de los cantos trata de las acciones de los dioses en el momento de la creación. Ellos crean el mundo con la fuerza de su pensamiento, « acordándose », « pensando con sus pensamientos » y « dialogando ». Tomando en cuenta el concepto de réplica, la totalidad de la creación está a cargo de la fuerza mágica y de los pensamientos del cantador. Como se dijo más arriba, entre los coras, el ritual no es alegoría, la representación no es drama sino dromenon (Preuss 19041905, 1912 ; Cassirer 1997b, p. 52 ; Neurath 1998, 2000).

Durante el canto el chamán dialoga con las deidades, quienes efectivamente asisten a las fiestas. En éstas, los hombres ofrecen a los dioses « todo lo que necesitan », desde réplicas en miniatura de su parafernalia ritual, tabaco, nubes de algodón y alimento hasta objetos que son el mundo mismo. Así, los hombres dialogan con los dioses, que son todos antepasados, a través del chamán. Simultáneamente, el chamán y otros participantes del ritual son los dioses mismos, que con sus acciones procuran a los hombres los medios necesarios para su subsistencia, desde las lluvias y el calor solar hasta su propio corazón (Neurath 1998).

No sólo la reciprocidad entre hombres y dioses es narrada en los cantos, sino que además éstos se ejecutan en contextos rituales caracterizados por el intercambio de dones. Puede decirse, entonces, que la intersubjetividad y la reciprocidad entre los antepasados (todos los dioses) y los hombres caracterizan un corpus literario que no está fijado por la escritura, sino que es siempre acción ritual. Y que simultáneamente esta acción es la condición de posibilidad de la objetivación del mundo.

\section{CONCLUSIONES}

La interpretación de la teoría de la religión y de la magia de Preuss a través del proyecto humboldtiano revela la afinidad de su pensamiento. La ampliación del concepto de lengua en Humboldt a otras formas de objetivación y unificación del saber se efectua atendiendo a la interrogante por el modo particular en que el objeto se sujeta al conocimiento y gana variedad interna en relación con la variedad de los 
principios cognitivos. El modo mágico de pensar, es pues un principio cognitivo. Las concepciones complejas son la forma formata y forma formans por mediación de las cuales se manifiesta la actividad intelectual.

El campo empírico de Humboldt son todas las lenguas conocidas (cf. Trabant 1994), el de Preuss, más modesto, le permite sin embargo hacer intervenir más dimensiones de la vida social, dando como resultado un conocimiento más profundo del carácter de estas etnias. La idea de Humboldt, de que sólo la elucidación del lenguaje, emprendida desde los enfoques comprensivo, comparativo, analítico y filosófico, podía dar acceso a un entendimiento genuino de la humanidad, « ubicó [su] propuesta en el centro de la problemática filosófica planteada por la crítica del conocimiento de Kant, y lo llevó a desarrollar una teoría del lenguaje, que es antropología » (Meschonnic 1982, p. 47, apud Trabant 1990, p. 56). Preuss practicó una antropología cuyo tratamiento de los fenómenos linguísticos realiza el proyecto de Humboldt. Él nos advierte que, se tomen o no en cuenta los fenómenos lingüísticos particulares o el lenguaje en general en el estudio antropológico de la humanidad, la concepción que se tenga del lenguaje humano siempre determinará la teoría antropológica.*

* Manuscrit reçu en mai 2002, accepté pour publication en juillet 2002.

\section{NOTES}

1. Cabe mencionar que el Plan einer vergleichenden Anthropologie data de 1795 (Humboldt 1968, I [1795], pp. 377-410), mientras que Über die Verschiedenheit des menschlichen Sprachbaues und ihren Einfluß auf die geistige Entwicklung des Menschengeschlechts, donde se encuentra una nueva formulación del mismo, apareció póstumamente en 1836 (Humboldt 1990).

2. Al respecto, Donatella Di Cesare llama la atención sobre el hecho de que « la obra de Humboldt carece de fórmulas fijas, de definiciones univocas y precisas, que permitan determinar por completo la esencia del lenguaje, que para Humboldt sólo se puede aprehender por medio de metáforas. Hay sin embargo una excepción : la definición de la lengua como enérgeia, que aparece una sola vez en la Einleitumg » (Di Cesare 1999 [1993], p. 90).

3. Preuss aclara que "Los términos " primitivos "o " pueblos naturales "que aquí se usan por falta de otro mejor no deben interpretarse como si pretendiéramos aclarar los origenes de la cultura. Denominamos "pueblos naturales" a las tribus que viven en un nivel cultural relativamente bajo y que no están influenciados por las naciones culturales occidentales u otras similares, sino de manera muy escasa » (Preuss 1914, p. 2).

4. "Genética ", diria Humboldt.

5. Aquí se propone que el término « idealismo » en la obra de Preuss ha de entenderse según la definición de Kant (1998, pp. 374 ss.).

6. Pero, a continuación, rechaza el postulado según el cual las formas religiosas primitivas carecen de sentido y explica que « cuando se alcanza la comprensión de las costumbres, a veces extrañas, se entiende que solamente quienes no se dedican al estudio de los pueblos primitivos pueden hablar de confusión » (Preuss 1914, p. 5), pues en definitiva, no existe tal cosa como la liberación de los principios de la magia y el culto, ya que, « en el desarrollo de la cultura intelectual, siempre entran en acción los mismos impulsos religiosos de la humanidad " (ibid.). 


\section{BIBLIOGRAFÍA}

AlCocer, Paulina, 2000a. - «El preanimismo de K. Th. Preuss como fundamento de la crítica de la conciencia mitológica en la Filosofia de las formas simbólicas de Ernst Cassirer », ponencia presentada en el I Congreso Iberoamericano de Filosofia de la Ciencia y de la Tecnología « El conocimiento y el desarrollo en el siglo XXI », Morelia, Michoacán.

—, 2000b. — « La magia en las palabras: Tylor, Preuss y Malinowski. El debate inconcluso entre animismo y preanimismo », comunicación idónea de resultados preliminares, Maestría en Humanidades, Departamento de Filosofía, Universidad Autónoma MetropolitanaIztapalapa, México.

Borsche, Tilman, 1990. — « Wilhelm von Humboldt », Große Denker, C. H. Beck, Munich, p. 519.

Bunzl, Matti, 1996. - « Franz Boas and the Humboldtian Tradition. From Volksgeist and Nationalcharakter to an Anthropological Concept of Culture », George W. Stocking Jr., Volksgeist as Method and Ethic. Essays on Boasian Ethnography and the German Anthropological Tradition, History of Anthropology, Vol. VIII, University of Wisconsin Press, Wisconsin.

Cassirer, Ernst, 1993a [1923]. - «Die Kantische Elemente in Wilhelm von Humboldts Sprachphilosophie », Ernst Cassirer. Geist und Leben. Schriften zu den Lebensordmungen von Natur und Kunst, Geschichte und Sprache (Ernst Wolfgang Orth, ed.), Reclam Verlag, Leipzig, pp. 236-273.

—, 1993b [1945]. — «Strukturalismus in der moderne Linguistik », Ernst Cassirer: Geist und Leben. Schriften zu den Lebensordnungen von Natur und Kunst, Geschichte uns Sprache (Ernst Wolfgang Orth, ed.), Reclam Verlag, Leipzig, pp. 317-346.

—, 1996. - The Philosophy of Symbolic Forms IV. The Metaphysics of Symbolic Forms (John Michael Krois \& Donald Phillip Verene, eds.), Yale University Press, New Haven.

—, 1997a [1923]. - Philosophie der symbolischen Formen I. Die Sprache, Primus Verlag, Darmstadt.

—, 1997b [1925]. — Philosophie der symbolischen Formen II. Das mythische Denken, Primus Verlag, Darmstadt,

—, 1997c [1929]. - Philosophie der symbolischen Formen III. Phänomenologie der Erkenntnis, Primus Verlag, Darmstadt.

Di Cesare, Donatella, 1999 [1993]. - Wilhelm von Humboldt y el estudio filosófico de las lenguas, Anthropos [Autores, Textos y Temas. Humanismo, IV], Barcelona.

Efrert, F. R., 1992. - J. P. B. de Josselin de Jong, Curator and Archaeologist. A Study of His Early Career (1910-1932), Centre of Non-Western Studies, Leiden.

Evans-Pritchard, Edward E., 1991 [1965]. - Las teorías de la religión primitiva, Siglo xxı editores, México.

Fischer, Hans, 1990. - Völkerkunde im Nationalsozialismus. Aspekte der Anpassung, Affinität und Behauptung einer wissenschaftlichen Diziplin, Dietrich Reimer Verlag, Berlin-Hamburg.

Humboldt, Wilhelm von, 1968, I [1795]. - «Plan einer vergleichenden Anthropologie », Wilhelm von Humboldts Gesammelte Schriften (A. Leitzmann et al., eds.), De Gruyter, Berlín, pp. 377-410. 
—, 1968, VII [1795-1796]. — « Über Denken und Sprechen », Wilhelm von Humboldts Gesammelte Schriften (A. Leitzmann et al., eds.), De Gruyter, Berlín, pp. 581-584.

—, 1968, II [1798]. - « Über Goethes Herrmann und Dorothea », Wilhelm von Humboldts Gesammelte Schriften (A. Leitzmann et al., eds.), De Gruyter, Berlín, pp. 115-319.

—, 1968, III [1806]. - « Latium und Hellas oder Betrachtungen über das klassische Alterthum ", Wilhelm von Humboldts Gesammelte Schriften III (A. Leitzmann et al., eds.), De Gruyter, Berlin, pp. 136-170.

—, 1968, V [1824-1826]. — « Grundzüge des allgemeinen Sprachtypus », Wilhelm von Humboldts Gesammelte Schriften V (A. Leitzmann et al., eds.), De Gruyter, Berlin, pp. 364-475.

—, 1990 [1836]. - Sobre la diversidad de la estructura del lenguaje humano y su influencia sobre el desarrollo espiritual de la humanidad, Anthropos [Autores, Textos y Temas, Lingüística, I], Barcelona.

—, 1994a [1820]. — « Über das vergleichende Sprachstudium in Beziehung auf die Verschiedenen Epochen der Sprachentwicklung », Über die Sprache. Reden vor der Akademie (Jürgen Trabant, ed.), Francke Verlag, Tübingen, pp. 11-32.

—, 1994b [1827]. — « Über den Dualis », Über die Sprache, Reden vor der Akademie (Jürgen Trabant, ed.), Francke Verlag, Tübingen, pp. 143-169.

JÁuregui, Jesús y Johannes Neurath, en prensa. - «El pasado prehispánico y el presente indigena : Seler, Preuss y las culturas del Gran Nayar », en : Flechadores de estrellas. Nuevas aportaciones a la etnología de los coras y huicholes, Instituto Nacional de Antropología e Historia/Universidad de Guadalajara, México, s. f.

JungBLuth, Hans, 1933. - Konrad Theodor Preuss und seine religionsgeschichtlichen Grundanschauungen. Inauguraldissertation zur Erlangung der Doktorwürde, Rheinische FriedrichWilhelms Universität Bonn, Triepel-Schulze, Breslau.

K^Nт, Immanuel, 1988 [1781]. - Kritik der reinen Vermunf, 2 vol., Suhrkamp, Frankfurt a.M.

Kutscher, Gerdt, 1976. - Berlin como centro de estudios americanistas. Ensayo biobibliográfico, Gebr. Mann Verlag, Berlin.

Lehmann, Walter, 1949 [1922]. — «Bibliografia de Eduard Seler con versión española de los títulos ", El México antiguo. Revista internacional de arqueología, etnología, folklore, prehistoria, historia antigua y lingüística mexicanas, México, 7, pp. 522-560.

Leenhardt, Maurice, 1997 [1947]. - Do kamo. La persona y el mito en el mundo melanesio, Paidós, Barcelona.

Malinowski, Bronislaw, 1961 [1922]. - The Argonauts of Western Pacific, E. P. Dutton \& Co. Inc., Nueva York.

Marett, Robert R., 1979 [1914]. - The Threshold of Religion, AMS Press, Nueva York.

Meschonnic, Henri, 1982. - Critique du rythme. Anthropologie historique du langage, Verdier, Lagrasse.

MÜLLER-VOLLMER, Kurt, 1994. - « Humboldts linguistisches Beschaffungsprogramm : Logistik und Theorie ", Wilhelm von Humboldt und die amerikanischen Sprachen (Klauss Zimmerman, Jürgen Trabant \& Kurt Müller-Vollmer, eds.), Ferdinand Schöningh, Paderborn, Munich, Viena y Zürich, pp. 27-42.

Neurath, Johannes, 1998. - Las fiestas de la casa grande : ritual, iniciación y cosmovisión en una comunidad wixarika (Tíapurie / Santa Catarina Cuexcomatitán), tesis de doctorado en Antropología, Universidad Nacional Autónoma de México, México.

—, 1999. - «Calendario solar y lucha cósmica : la vigencia del concepto de religión astral en el Gran Nayar ", ponencia presentada en el Simposio Antropología e historia del Nayarit, Tepic, Nayarit. 
—, 2000. — «El don de ver. El proceso de iniciación y sus implicaciones para la comovisión huichola ", Desacatos 5. Revista de Antropología Social, Centro de Investigación y Estudios Superiores en Antropología Social, México, pp. 57-77.

Neurath, Johannes y Jesús Jáuregui, 1998. — « La expedición de Konrad Theodor Preuss al Nayarit (1905-1907) y sus contribuciones a la mexicanística ", Fiesta, literatura y magia en el Nayarit. Ensayos sobre coras, huicholes y mexicaneros de Konrad Theodor Preuss (Jesús Jáuregui y Johannes Neurath, comps.), Instituto Nacional Indigenista-Centro Francés de Estudios Mexicanos y Centroamericanos, México, pp. 15-60.

Nicholson, H. B., 1973. - «20. Eduard Georg Seler (1849-1922)», Guide to Ethnohistorical Sources. Part Two (Howard F. Cline \& John B. Glass, eds.), Handbook of Middle American Indians, Vol. xıI (Robert Wauchope, gral. ed.), University of Texas Press, Austin, pp. 348369.

Penniman, T. K., 1965 [1935]. - A Hundred Years of Anthropology, Gerald Druckworth \& Co. Ltd., Londres.

Preuss, Konrad Theodor, 1894. - Die Begräbnisarten der Amerikaner und Nordasiaten, Inauguraldissertation zur Erlangung der Doktorwürde von der philosophischen Fakultät der Albertus-Universität zur Königsberg in Preussen, Hartungsche Buchdruckerei, Kaliningrado.

—, 1899. — «Die Zauberbilderschriften der Negrito in Malaka » I y II, Globus. Illustrierte Zeitschrift für Länder- und Völkerkunde, Brunswick, 75 (22), pp. 345-348, (23), pp. 364-369.

—, 1904. - « Der Ursprung der Religion und Kunst. Vorläufige Mitteiling von K. Th. Preuss », Globus. Illustrierte Zeitschrift für Länder-und Völkerkunde, 86 (20, 22, 23, 24), pp. 321-327, $355-363,375-379,388-393 ; 87(19,22,23,24)$.

—, 1905. - « Der Ursprung der Religion und Kunst. Vorläufige Mitteiling von K. Th. Preuss », Globus. Illustrierte Zeitschrift für Länder- und Völkerkunde, 86 (20, 22, 23, 24), 1904, pp. 321-327, 355-363, 375-379, 388-393 ; 87 (19, 22, 23, 24), pp. 333-337, 380-384, 394-400, 413-419.

—, 1905. - « Der Kampf der Sonne mit den Sternen in Mexiko », Globus. Illustrierte Zeitschrift für Länder-und Völkerkunde, Brunswick, 87 (7), pp. 136-140.

—, 1908. - «Unter den Indianern der Sierra Madre in Mexiko », Die Woche, 43, pp. 19081911.

—, 1912. - Die Nayarit-Expedition. Textaufnahmen und Beobachtungen unter mexikanischen Indianern I. Die Religion der Cora-Indianer in Texten nebst Wörterbuch, B. G. Teubner, Leipzig.

—, 1913. - « Die magische Denkweise der Cora-Indianer », xxıI International Congress of Americanists, London, May 17 to June $1^{\text {st }}, 1912$, Londres, Harrison and Sons, 1, pp. 129 134.

—, 1914. - Die geistige Kultur der Naturvölker, B. G. Teubner, Leipzig.

—, 1923. — «Die wissenschaftliche Lebensarbeit Eduard Selers », Zeitschrift fïr Ethnologie, 55, Berlín, pp. 1-6.

—, 1976 [1908]. — « Die religiösen Gesänge und Mythen einiger Stämme der mexikanischen Sierra Madre ", Nahua-Texte aus San Pedro Jicora in Durango III. Gebete und Gesänge. Aufgezeichnet von Konrad Theodor Preuss. Aus dem Nachlass übersetzt und herausgegeben von Elsa Ziehm, Iberoamerikanisches Institut Berlin Preussischer Kulturbesitz, Gebrüder Mann Verlag, Berlin, pp. 19-33 (Quellenwerke zur alten Geschichte Amerikas aufgezeichnet in den Sprachen der Eingeborenen, 11). 
Radcliffe-Brown, A. R., 1935. - " On the concept of function in social science », American Anthropologist, n.s., 37, pp. 394-404.

—, 1949. — «Functionalism. A protest », American Anthropologist, n.s., 51, pp. 320-323.

—, 1958 [1923]. — « The methods of ethnology and social anthropology », Method in social anthropology, M. N. Srinivas, Chicago, pp. 3-38.

SChlenther, Ursula, 1959-1960. — «Zur Geschichte der Völkerkunde an der Berliner Universität von 1810 bis 1945 », Wissenschaftliche Zeitschrift der Humboldt-Universität zu Berlin, Berlín, Beiheft zum Jubiläumsjahrgang, 9, pp. 67-79.

SCHMidT, P. Wilhelm \& P. W. Koppers, 1924. - Völker und Kulturen I. Gesellschaft und Wirtschaft der Völker, Regensburg.

Trabant, Jürgen, 1986. - Apeliotes oder der Sinn der Sprache. Wilhelm von Humboldts SprachBild, Wilhelm Fink Verlag, Munich.

—, 1990. — Traditionen Humboldts, Suhrkamp, Frankfurt a.M.

—, 1994. — « Ein weites Feld : Les langues du nouveau continent ", Wilhelm von Humboldt und die amerikanischen Sprachen (Klauss Zimmerman, Jürgen Trabant \& Kurt Müller-Vollmer, eds.), Ferdinand Schöningh, Paderborn, Munich, Viena y Zürich, pp. 11-25.

—, 2000. — « Le courant humboldtien », Histoire des idées linguistiques III (Sylvain Auroux, ed.), Mardaga, Bruxelles, pp. 311-322.

TYLor, Edward B., 1977 [1871]. - Cultura primitiva I. Los orígenes de la cultura, Editorial Ayuso, Madrid.

Westphal-Hellbusch, Sigrid, 1969-1971. - «Hundert Jahre Ethnologie in Berlin unter besonderer Berücksichtigung ihrer Entwickelung an der Universität », 100 Jahre Berliner Gesellschaft für Anthropologie, Ethnologie und Urgeschichte 1869-1969, Berlin.

Wittgenstein, Ludwig, 1997 [1967]. - Comentarios sobre La rama dorada, Universidad Nacional Autónoma de México, México. 